\title{
Metode SQ3R Untuk Meningkatkan Hasil Belajar PPKn Siswa Sekolah Dasar
}

\author{
Mita Rifdayanti*, Mubarak Ahmad \\ Program Studi PGSD,Universitas Muhammadiyah Prof. Dr. Hamka, Jakarta, Indonesia \\ *Coresponding Author: mitharifdha@gmail.com
}

Article History:

Received 2021-09-09

Revised 2022-01-03

Accepted 2022-01-22

DOI:

10.31949/educatio.v8i1.1484

\begin{abstract}
This research is motivated by the problem of the low learning outcomes of students in Pancasila and Citizenship Education (PPKn) subjects. The solution made from these problems is to apply the SQ3R learning method. This study aims to determine the effect of the SQ3R method on student learning outcomes in Civics subjects. The research method used is quantitative with a quasiexperimental design. The population in this study were students of class $V$ at SDN Tangerang 15. The sample selected was two classes, namely students in class $V A$ and VB at SDN Tangerang 15 with a total of 36 students. The instrument used in this research is the PPKN study test. To analyze the data using the average difference test with a significant level of $5 \%$. The results showed that student learning outcomes in Civics Class V A and Class V B learning increased after being given treatment. However, the average value of student learning outcomes using the SQ3R learning model is better than the average student learning outcomes using conventional learning models. Thus the SQ3R model is more effective in improving the learning outcomes of Class $V$ students in Civics.

Keywords: SQ3R learning method; learning outcomes; primary school.
\end{abstract}

\begin{abstract}
Abstrak
Penelitian ini dilatarbelakangi dengan masalah tentang rendahnya hasil bilajar siswa pada mata pelajaran Pendidikan Pancasila dan Kewarganegaraan (PPKn). Solusi yang dibuat dari permasalah tersebut adalah dengan menerapkan metode pembalajaran SQ3R. Penelitian ini bertujuan untuk mengetahui pengaruh metode SQ3R terhadap hasil belajar siswa pada mata pelajaran PPKn. Metode penelitian yang digunakan adalah kuantitatif dengan desain Quasi eksperimen. Populasi dalam penelitian ini adalah siswa kelas V SDN Tangerang 15. Sampel yang dipilih sebanyak dua kelas, yaitu siswa kelas VA dan VB SDN Tangerang 15 dengan total sebanyak 36 siswa. Instrumen yang digunakan dalam penelitian ini adalah soal tes belajar PPKN. Untuk menganalisis data menggunakan uji perbedaan rata-rata dengan taraf signifikan 5\%. Dari hasil penelitian menunjukkan hasil belajar siswa dalam pembelajaran PPKn Kelas V A dan Kelas V B meningkat setelah diberikan perlakuan. Namun nilai rata-rata hasil belajar siswa dengan menggunakan model pembelajaran SQ3R lebih baik dibanding rata-rata hasil belajar siswa dengan menggunakan model pembelajaran konvensional. Dengan demikian model SQ3R lebih efektif dalam meningkatkan hasil belajar siswa Kelas V pada mata pelajaran PPKN.
\end{abstract}

Kata Kunci : metode pembelajaran SQ3R; hasil belajar; sekolah dasar.

\section{PENDAHULUAN}

Pendidikan Pancasila dan Kewarganegaraan (PPKn) adalah salah satu mata pelajaran yang diajarkan di jenjang sekolah dasar. Mata pelajaran ini diberikan kepada siswa sebagai wahana untuk mengembangkan dan melestarikan nilai luhur dan moral yang berakar pada budaya Indonesia, serta diharapkan dapat diwujudkan dalam kehidipan sehari-hari peserta didik (Jasrudin et al, 2020; Mitha, 2014; Nasozaro, 2019; Susetyo, 2018) baik sebagai individu maupun anggota masyarakat dan makhluk ciptaan Tuhan Yang Maha Esa. PPKn menanamkan cinta tanah air dan menjadikan warga negara yang baik dan mempunyai kontribusi terhadap bangsa dan negara (Mamonto et al, 2020; Sulianti, 2018; Syam, 2011). 
PPKn adalah pendidikan tentang nilai-nilai yang sasarannya bukan semata-mata pengalihan pengetahuan melainkan lebih ditekankan pada pembentukan sikap (Andayani, 2015; Nirmayani, 2020). Dengan demikian, mata pelajaran ini meliputi ranah kognitif, afektif, dan psikomotor dengan menitikberatkan ranah afektif. Tugas untuk melaksanakan misi tersebut bukanlah hal yang mudah dan diperlukan suatu pembelajaran yang tepat agar misi yang diembannya dapat tercapai. Untuk menanamkan nilai-nilai yang dikehendaki ini tentu saja melalui proses pembelajaran yang benarbenar tepat bagi pembelajaran pendidikan nilai agar pembentukan kepribadian siswa dapat tercapai. PPkn diberikan kepada siswa dengan tujuan mengembangkan moral serta meningkatkan mutu kehidupan dan martabatnya kelak sebagai warga negara Indonesia yang berkepribadian Indonesia sesuai dengan tujuan pendidikan nasional.

Dalam rangka mencapai tujuan bidang studi ini, para guru seharusnya telah menerapkan suatu pembelajaran yang memfasilitasi pengetahuan siswa pada saat pembelajaran di kelas. Namun pada kenyataannya, pembelajaran PKn di kebanyakan sekolah dasar belum menerapkan strategi pembelajaran yang tepat. Akibatnya hasil belajar yang diperoleh dalam pembelajaran PPKn belum sesuai dengan apa yang telah ditetapkan. Beberapa penelitian juga mengungkap permasalahan hasil belajar siswa pada mata pelajaran PPKn, seperti penelitian yang dilakukan Mediatati \& Suryaningsih (2017), Setiyawan \& Yunianta (2018), Soleha \& Rahayu (2021), dan Irwan \& Hasnawi (2021).

Dalam proses pembelajaran terdapat hubungan yang era antara strategi dengan metode. Untuk mencapai hasil pembelajaran yang maksimal, diperlukan strategi pembelajaran yang tepat. Pada saat menetapkan strategi yang digunakan, guru harus cermat dalam memilih dan menetapkan metode yang sesuai. Tujuan pembelajaran merupakan salah satu aspek yang perlu dipertimbangkan dalam merencanakan pembelajaran, sebab segala kegiatan pembelajaran, sebab segala kegiatan pembelajaran bermuara pada tercapainya tujuan tersebut. (Uno, 2016). Oleh karena itu diperlukan keterampilan memilih dan menggunakan metode mengajar untuk diterapkan dalam sistem pembelajaran yang efektif sehingga akan membawa siswa ke dalam situasi belajar yang bervariasi dan siswa terhindar dari situasi pengajaran yang membosakan. Memilih metode pembelajaran yang tepat merupakan suatu keterampilan yang harus dimiliki oleh guru agar didapatkan metode untuk mencapai tujuan pembelajaran dengan baik. Pemilihan metode pembelajaran mata pelajaran PPKn pada umumnya didasarkan pada tujuan pembelajaran, materi pembelajaran, waktu pembelajaran, keterampilan dan pengalaman guru dalam mengelola metode pembelajaran.

Sejumlah metode yang biasa digunakan dalam belajar mengajar, antara lain adalah metode ceramah, tanya jawab, diskusi, demonstrasi, percobaan atau eksperimen, Latihan atau simulasi, kerja kelompok, karya wisata dan sosiodarma atau bermain peran (role playing). (Ibrahim \& Syaodih. S, 2002). Metode belajar tersebut adalah metode belajar SQ3R (Survey, Question, Read, Recite, Revien) yaitu suatu kiat belajar yang secara spesifik dirancang untuk memahami isi teks, bersifat praktis dan dapat diaplikasikan dalam berbagai pendekatan belajar (Syah, 2013). Model pembelajaran SQ3R adalah model pembelajaran yang menggunakan strategi membaca dengan menugaskan siswa untuk membaca bahan belajar secara seksama (Harahap \& Lubis, 2020; Suardani et al, 2013). Permasalahan yang sering dihadapi dalam proses pembelajaran adalah keaktifan siswa dalam memperdalam konsep yang ada terkait dengan materi ajar kurang. Siswa sering lebih pasif dalam menguasai kompetensi tertentu. Model pembelajaran kooperatif tipe SQ3R bertujuan agar pembaca aktif dalam menghadapi bacaan dan dapat menemukan ide pokok serta detail penting yang mendukung ide pokok tersebut. Metode SQ3R ini sangat tepat digunakan dengan melihat keadaan sebagian besar siswa yang tidak tertarik membaca karena sulit dipahami. Dari latar belakang tersebut, maka penelitian ini bertujuan untuk mengetahui peningkatan hasil belajar siswa dalam pembelajaran dengan metode belajar SQ3R.

\section{METODE PENELITIAN}

Metode penelitian yang digunakan dalam penelitian ini adalah metode kuantitif dengan eksperimen kuasi. Penelitian dilaksanakan di SDN Tangerang 15 yang beralamat di Jalan Perintis Kemerdekaan No.39, RT.006/RW.003, Babakan, Kec. Tangerang, Kota Tangerang, Banten. Waktu penelitian berlangsung selama 7 bulan terhitung sejak Januari sampai bulan Juli 2021. 
Populasi dalam penelitian ini adalah seluruh siswa Kelas V SDN Tangerang 15 Kota Tangerang Tahun Pelajaran 2020/2021, yang berjumlah 36 siswa. Sampel yang dipilih sebanyak dua kelas, yaitu siswa kelas VA sebagai kelas eksperimen dan siswa kelas VB sebagai kelas kontrol.

Pengumpulan data dilakukan dengan menggunakan angket dan pretest/postest sebagai akhir dari tes pelaksanaan. Data tentang Metode SQ3R diperoleh melalui angket dalam bentuk instrumen penelitian yang disebarkan kepada seluruh responden. Sedangkan data mengenai hasil belajar PPKn diperoleh melalui tes yang dibuat khusus untuk kepentingan tersebut dan disesuaikan dengan kurikulum yang berlaku.

\section{HASIL DAN PEMBAHASAN}

Uji coba dilakukan di SDN Tangerang 15 dengan jumlah 20 siswa. Uji coba dilakukan untuk mengetahui validitas dan realibilitas instrumen.

Dari 20 soal uji coba instrumen dinyatakan bahwa seluruh instrument dinyatakan valid, dikarenakan $r$ hitung lebih besar dari $\mathrm{r}$ tabel pada taraf signifikan 5\% dengan n 20 yaitu 0,444 . Dari perhitungan yang dilakukan juga didapatkan nilai $\mathrm{r}$ sebesar 0.790. Maka dapat disimpulkan instrumen tes hasil belajar reliabel dengan kriteria tinggi.

1. Hasil Belajar Kelas Eksperimen.

Tabel 1. Hasil Belajar Kelas Eksperimen Sebelum perlakuan (pre-test)

\begin{tabular}{lcc}
\hline & & Pre-test kelompok Eksperimen \\
\hline $\mathrm{N}$ & Valid & 18 \\
& Missing & 18 \\
& & \\
Mean & 67.44 \\
Median & 68.50 \\
Mode & 65.00 \\
Std. Deviation & 6.810 \\
Minimum & 54.00 \\
Maximum & 75.00 \\
\hline
\end{tabular}

Hasil perhitungan dengan menggunakan SPSS 21.00 pada data sebelum perlakuan (pre-test) pada kelas eksperimen didapat jumlah sampel yang valid 18 , skor rerata $=67.44$, nilai tengah $=68.50$, simpangan baku $=6.810$, nilai minimum $=54$ dan nilai maksimum $=75$.

Tabel 2. Hasil Belajar Kelas Eksperimen Setelah Perlakuan (Post-Test)

\begin{tabular}{|c|c|c|}
\hline & & Post-test kelompok Eksperimen \\
\hline $\mathrm{N}$ & $\begin{array}{l}\text { Valid } \\
\text { Missing }\end{array}$ & $\begin{array}{l}18 \\
18\end{array}$ \\
\hline Mean & & 85.17 \\
\hline Median & & 85.50 \\
\hline Mode & & 80.00 \\
\hline Std. Deviation & & 3.714 \\
\hline Minimum & & 80.00 \\
\hline Maximum & & 92.00 \\
\hline
\end{tabular}

Hasil perhitungan dengan SPSS 21 setelah perlakuan pada kelas eksperimen didapatkan jumlah sampel yang valid $=18$, skor rata-rata $=85.17$, nilai tengah $=85.50$, standar deviasi $=3.714$, nilai minimum $=80$, nilai maksimum $=92$.

2. Hasil Belajar Kelas Kontrol

Hasil perhitungan dengan menggunakan SPSS 21 data hasil belajar siswa di kelas kontrol sebelum perlakuan dapat dilihat pada tabel 3. Data pada tabel 3 menunjukkan sebelum perlakuan kelas kontrol 
didapat jumlah sampel yang valid 18 , skor rerata $=67.50$ nilai tengah $=69.50$, simpangan baku $=7.540$ nilai minimum $=54$ dan nilai maksimum $=81$.

Tabel 3. Hasil Belajar Kelas Kontrol Sebelum Perlakuan (Pre-Test)

\begin{tabular}{lcc}
\hline & & Pre-test kelompok Kontrol \\
\hline $\mathrm{N}$ & Valid & 18 \\
& Missing & 18 \\
Mean & \\
Median & 67.50 \\
Mode & 69.50 \\
Std. Deviation & 70.00 \\
Minimum & 7.540 \\
Maximum & 54.00 \\
\hline
\end{tabular}

Hasil perhitungan dengan menggunakan SPSS 21 data hasil belajar siswa di kelas kontrol setelah perlakuan dapat dilihat pada tabel 4 .

Tabel 4. Hasil Belajar Kelas Kontrol Setelah Perlakuan (Post-Test)

\begin{tabular}{lcc}
\hline & Post-test kelompok Kontrol \\
\hline $\mathrm{N}$ & Valid & 18 \\
& Missing & 18 \\
Mean & \\
Median & 77.28 \\
Mode & 78.50 \\
Std. Deviation & 79.00 \\
Minimum & 5.486 \\
Maximum & 67.00 \\
\hline
\end{tabular}

Hasil perhitungan dengan menggunakan SPSS 21 pada data setelah perlakuan pada kelas kontrol didapat jumlah sampel yang valid 18 , skor rerata $=77.28$ nilai tengah $=78.50$, simpangan baku $=5.486$ nilai minimum $=67$ dan nilai maksimum $=89$.

Penelitian ini bertujuan untuk mengetahui perbedaan metode SQ3R dan metode Konvensional dalam meningkatkan hasil belajar siswa pada pembelajaran PPKn Keas V SDN Tangerang 15. Untuk mengetahui perbedaan rata-rata dua sampel yang berpasangan maka dilakukan Paired Sample T-Test. Dua sampel ini sebelumnya telah dinyatakan berdistribusi normal dan homogen.

Tabel 5. Ringkasan Paired Sample T Test

\begin{tabular}{|c|c|c|c|c|c|c|}
\hline & & \multicolumn{2}{|c|}{ Paired Differences } & \multirow[b]{2}{*}{$\mathrm{t}$} & \multirow[b]{2}{*}{ df } & \multirow{2}{*}{$\begin{array}{l}\text { Sig. (2- } \\
\text { tailed) }\end{array}$} \\
\hline & & Mean & Std. Deviation & & & \\
\hline Pair 1 & $\begin{array}{l}\text { Pre-Test Eksperomen - } \\
\text { Post-Test Eksperimen }\end{array}$ & $-17,722$ & 7,653 & $-9,825$ & 17 & ,000 \\
\hline Pair 2 & $\begin{array}{l}\text { Pre-Test Kontrol - } \\
\text { Post-Test Kontrol }\end{array}$ & $-9,778$ & 7,125 & $-5,822$ & 17 & ,000 \\
\hline
\end{tabular}

Berdasarkan output Pair 1 diperoleh nilai Sig (2-tailed) sebesar 0,000 < dari 0,05, maka dapat disimpulkan terdapat perbedaan rata-rata hasil belajar siswa Pre-Test Kelas Eksperimen dengan Post-Test Kelas Eksperimen. Selanjutnya berdasarkan output Pair 2 diperoleh nilai Sig (2-tailed) sebesar 0,000 < dari 0,05, maka dapat disimpulkan terdapat perbedaan rata-rata hasil belajar siswa Pre-Test Kelas Kontrol dengan Post-Test Kelas Kontrol. Beradasarkan hasil tersebut maka dapat disimpulkan bahwa terdapat pengaruh model pembelajaran SQ3R terhadap hasil belajar PPKn siswa. 
Untuk mengetahui seberapa besar pengaruh pembelajaran SQ3R terhadap hasil belajar siswa pada mata pelajaran PPKn dapat dilihat pada tabel 6.

Tabel 6. Data Statistis Uji Paired Sample T Test

\begin{tabular}{llccc}
\hline & & Mean & N & Std. Deviation \\
\hline Pair 1 & Pre-Test Kelas Eksperimen & 67,44 & 18 & 6,810 \\
& Post-Test Kelas Eksperimen & 85,17 & 18 & 3,714 \\
\multirow{2}{*}{ Pair 2 } & Pre-Test Kelas Kontrol & 67,50 & 18 & 7,540 \\
& Post-Test Kelas Kontrol & 77,28 & 18 & 5,486 \\
\hline
\end{tabular}

Berdasarkan tabel 6 terlihat adanya peningkatan hasil belajar siswa pada mata pelajaran PPKn dengan menggunakan metode SQ3R. Dimana nilai rata-rata hasil belajar Pre-Test siswa Kelas Eksperimen sebesar 67,44 dan hasil belajar Post-Test siswa Kelas Eksperimen sebesar 85,17.

3. Uji Perbedaan rata-rata

Untuk mengetahui apakah terdapat perbedaan rata-rata dua sampel yang tidak berpasangan maka dilakukan uji perbedaan rata-rata dengan Independent Sample T Test. Berdasarkan perhitungan sebelumnya bahwa data Post Test Kelas Eksperimen dan data Post Test Kelas Kontrol berdistribusi normal dan homogen.

Independent Sample T Test dalam penelitian ini digunakan untuk mengetahui ada atau tidaknya perbedaan hasil belajar siswa pada mata pelajaran PPKn antara yang diajar dengan metode SQ3R dengan metode konvensional. Untuk menjawab masalah tersebut dilakukan Independent Sample T Test terhadap data Post Test Kelas Eksperimen dan data Post Test Kelas Kontrol. Adapun hasil Independent Sample T Test yang telah dilakukan diperoleh hasil sebagaimana tertuang dalam tabel 7.

Tabel 7. Uji Paired Sample T Test

\begin{tabular}{|c|c|c|c|c|c|c|}
\hline & & \multicolumn{2}{|c|}{ Paired Differences } & \multirow[b]{2}{*}{$\mathrm{t}$} & \multirow[b]{2}{*}{ df } & \multirow{2}{*}{$\begin{array}{l}\text { Sig. }(2- \\
\text { tailed) }\end{array}$} \\
\hline & & Mean & Std. Deviation & & & \\
\hline Pair 1 & $\begin{array}{l}\text { Pre-Test Eksperomen - } \\
\text { Post-Test Eksperimen }\end{array}$ & 17,722 & 7,653 & $-9,825$ & 17 &, 000 \\
\hline Pair 2 & $\begin{array}{l}\text { Pre-Test Kontrol - } \\
\text { Post-Test Kontrol }\end{array}$ & $-9,778$ & 7,125 & $-5,822$ & 17 & ,000 \\
\hline
\end{tabular}

Berdasarkan hasil pada tabel 7 diperoleh nilai Sig (2-tailed) sebesar 0,000 < dari 0,05, maka dapat disimpulkan bahwa terdapat perbedaan rata-rata hasil belajar siswa antara model pembelajaran SQ3R dengan model konvensional. Untuk mengetahui seberapa besar perbedaan rata-rata hasil belajar siswa antara model pembelajaran SQ3R dengan model konvensional dapat dilihat pada tabel 8.

Tabel 8. Statistik Uji Independent Sample T Test

\begin{tabular}{llccr}
\hline & Kelas & N & Mean & \multicolumn{1}{c}{ Std. Deviation } \\
\hline Hasil Belajar & Post Test Kelas & \multirow{2}{*}{18} & 85,17 & 3,714 \\
Siswa & Eksperimen & & & \\
& Post Test Kelas & 18 & 77,28 & 5,486 \\
& Kontrol & & & \\
\hline
\end{tabular}

Berdasarkan tabel 8 diperoleh nilai rata-rata hasil belajar siswa dengan menggunakan model pembelajaran SQ3R sebesar 85,17 dan rata-rata hasil belajar siswa dengan menggunakan model pembelajaran konvensional sebesar 77,28. Dengan demikian dapat disimpulkan bahwa penerapan pembelajaran model SQ3R pada mata pelajaran PPKN siswa Kelas V SDN Tangerang 15 lebih efektif dari model pembelajaran konvensional. Perbedaan rata-rata hasil Post-Test sebesar 7.89. 
Pada pembelajaran PPKn Siswa kelas V SDN Tangerang 15 dengan menggunakan Metode SQ3R berdasarkan hasil uji $\mathrm{t}$ diketahhui rata-rata pre-test 67,44 setelah dilakukan post-test naik menjadi 85,17 sehingga peningkatannya sebesar 17,73 . Selanjutnya berdasarkan uji t diperoleh nilai signifikansinya lebih kecil dari $0,05(0,00<0,05)$ sehingga dapat dinyatakan terdapat peningkatan secara signifikan pada skor hasil belajar siswa kelompok eksperimen atau yang diberikan metode SQ3R.

Pada Pembelajaran PPKn Siswa kelas V SDN Tangerang 15 dengan menggunakan Metode Konvensional Berdasarkan hasil uji t diketahui rata-rata pre-test sebesar 67,50 pada saat post-test meningkat menjadi 77,28, sehingga peningkatannya sebesar 9,78. Selanjutnya berdasarkan uji t diperoleh nilai signifikansinya kurang dari 0,05 (Sig $=0,000<0,05$ ). Dari data diatas dapat disimpulkam bahwa peningkatan sebesar 9,78 signifikan atau terdapat peningkatan secara signifikan pada skor hasil belajar siswa kelompok kontrol.

Pada Perbedaan rata-rata hasil belajar PPKn siswa kelas V SDN Tangerang 15 antara kelas eksperimen dan kelas kontrol Berdasarkan uji t post-test diketahui rata-rata hasil belajar kelas eksperimen sebesar 85,17 dan rata-rata hasil belajar kelas kontrol sebesar 77,28, sehingga dapat diimpulkan bahwa rata-rata hasil belajar kelas eksperimen lebih besar dibandingkan dengan kelas kontrol. Dengan demikian dapat penerapan pembelajaran model SQ3R pada mata pelajaran PPKN lebih baik dalam meningkatkan hasil belajar siswa Kelas V SDN Tangerang 15 dibandingkan model pembelajaran konvensional. Hasil penelitian ini sekaligus menguatkan penelitian yang dilakukan oleh Winarni (2021), Wahyudi et al (2021), dan Setiawan et al (2018) yang menyatakan bahwa model pembelajaran SQ3R adalah pembelajaran yang tepat untuk diterapkan pada mata pelajaran PKn, dan efektif dalam meningkatkan hasil belajar siswa.

\section{KESIMPULAN}

Berdasarkan data tersebut maka dapat disimpulkan bahwa terdapat pengaruh model pembelajaran SQ3R terhadap hasil belajar PPKn siswa. Adapun peningkatan hasil belajar siswa pada mata pelajaran PPKn dengan menggunakan metode SQ3R diperoleh nilai rata-rata hasil belajar Pre-Test siswa Kelas Eksperimen sebesar 67,44 dan hasil belajar Post-Test siswa Kelas Eksperimen sebesar 85,17. Keberhasilan siswa dalam belajar dipengaruhi oleh banyak faktor. Salah satu faktor tersebut adalah metode mengajar dengan menggunakan metode pembelajaran SQ3R. untuk itu, hendaknya guru dapat menggunakan metode pembelajaran SQ3R sehingga siswa dapat terlibat langsung dalam proses pemebelajran sehingga lebih menyenangkan dan tidak membosankan.

\section{DAFTAR PUSTAKA}

Andayani, S. (2015). Meningkatkan Hasil Belajar Siswa Melalui Penerapan Model Pembelajaran Tai (Team Assisted Individualization) Pada Mata Pelajaran Pkn Kelas Iv Sdn Gadingrejo 01 Kecamatan Umbulsari Kabupaten Jember. Pancaran Pendidikan, 4(4), 37-48.

Harahap, R. R. R., \& Lubis, R. (2020). Penggunaan Metode Sq3r Terhadap Hasil Belajar Akuntansi Siswa. Jurnal Pendidikan IPS, 1(1), 30-38.

Irwan, I., \& Hasnawi, H. (2021). Analisis Model Pembelajaran Contextual Teaching and Learning dalam Meningkatkan Hasil Belajar PPKn di Sekolah Dasar. EDUKATIF: Jurnal Ilmu Pendidikan, 3(1), 235-245.

Jasrudin, J., Putera, Z., \& Wajdi, F. (2020). Membangun Karakter Peserta Didik Melalui Penguatan Kompetensi PKn Dan Penerapan Alternatif Pendekatan Pembelajaran. Jurnal Pendidikan Kewarganegaraan, 10(2), 42-52.

Mamonto, P. W., Pasandaran, S., \& Pangalila, T. (2020). Peran guru PKn dalam menanamkan karakter cinta tanah air pada siswa di SMP Negeri 6 Kotamobagu. Jurnal Civic Education: Media Kajian Pancasila dan Kewarganegaraan, 4(1). 
Mediatati, N., \& Suryaningsih, I. (2017). Penggunaan model pembelajaran Course Review Horay dengan media flipchart sebagai upaya meningkatkan hasil belajar PKn. Jurnal Ilmiah Sekolah Dasar, 1(2), 113-121.

Mitha, M. (2014). Internalisasi Nilai Nasionalisme Dalam Pembelajaran PKN Pada Siswa MAN 2 Model Banjarmasin. Jurnal Pendidikan Kewarganegaraan, 4(8).

Muhibbin Syah. (2013). Psikologi Pendidikan dengan Pendekatan Baru. Remaja Rosdakarya.

Nasozaro, H. O. (2019). Pembangunan Karakter Bangsa Melalui Pendidikan Kewarganegaraan. Warta Dharmawangsa, 13(4).

Nirmayani, L. H. (2020). Peningkatan Kualitas Pembelajaran PKn di Sekolah Dasar Melalui Model Pengajaran Bermain Peran. Edukasi: Jurnal Pendidikan Dasar, 1(2), 207-215.

Setiawan, A., Ismail, I., \& Yuliatin, Y. (2018). Pengaruh Metode Pembelajaran SQ3R (Survey, Question, Read, Recite and Review) berpaduan Snowball Throwing terhadap Hasil Belajar Siswa pada Mata Pelajaran PPKn di SMPN 1 Mataram. Jurnal Pendidikan Sosial Keberagaman, 5(2).

Setiyawan, H., \& Yunianta, T. N. H. (2018). Upaya Meningkatkan Hasil Belajar PKn melalui Model Pembelajaran Kooperatif Tipe Take and Give pada siswa Sekolah Dasar. JPsd (Jurnal Pendidikan Sekolah Dasar), 4(2), 162-174.

Soleha, F., \& Rahayu, D. W. (2021). Model Pembelajaran Contextual Teaching And Learning untuk Meningkatkan Hasil Belajar Pkn di Sekolah Dasar. Jurnal BASICEDU: Journal of Elementary Education, 5(5), 3117-3124.

Suardani, N. L., Ardana, I. K., \& Putra, I. K. A. (2013). Pengaruh Model Pembelajaran SQ4R terhadap Keterampilan Membaca dalam Pembelajaran Bahasa Indonesia Siswa Kelas V Sd Gugus I Denpasar Selatan. MIMBAR PGSD Undiksha, 1(1).

Sulianti, A. (2018). Pendidikan Kewarganegaraan dalam Budaya Multikultural untuk Menanamkan Sikap Patriotisme Warga Negara. Jurnal: Pancasila dan Kewarganegaraan, 3(2), 17.

Susetyo, D. I. (2018). Strategi Guru Pendidikan Pancasila Dan Kewarganegaraan Dalam Membentuk Karakter Peserta Didik Di Sma Negeri 1 Ponorogo Dan Sma Muhammadiyah 1 Ponorogo. Edupedia, 2(1), 73-86.

Syam, N. (2011). Peningkatan Kualitas Pembelajaran Pkn di Sekolah Dasar melalui Model Pengajaran Bermain Peran. Perspektif Ilmu Pendidikan, 24(XV), 108-112.

Uno, H. B. (2016). Perencanaan Pembelajaran. PT Bumi Aksara.

Wahyudi, A., Pangestu, W. T., \& Wana, P. R. (2021). Upaya Peningkatan Hasil Belajar Siswa Materi Berorganisasi Pelajaran Pkn Dengan Menggunakan Model Pembelajaran Sq3r Pada Siswa Kelas V Semester 2 Sd Al-Azhar Kecamatan Kedunggalar Kabupaten Ngawi. Education and Learning of Elementary School, 1(02).

Winarni, P. (2021). Penggunaan Model Pembelajaran SQ3R (Survey, Question, Read, Recite, Review) Sebagai Upaya Meningkatkan Prestasi Belajar Pkn Siswa. Mimbar Pendidikan Indonesia, 1(3). 